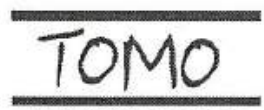

Artigo recebido e publicado em 2004

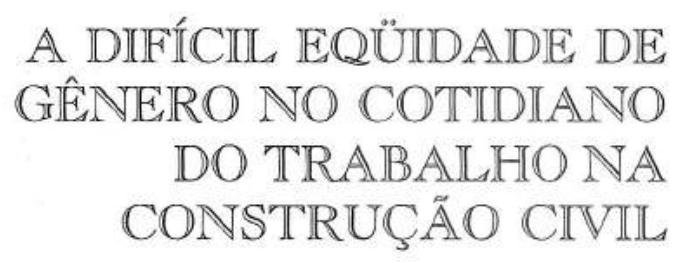

Maria Helena Santana Cruz

estudo visa ampliar a produção do conhecimento sobre gênero
e trabalho no contexto das transformações mundiais que atingem o conjunto das relações sócio-culturais e econômicas das sociedades industrializadas produzindo impactos diferenciados, de acordo com os contextos sócio-econômicos em setores específicos. Essa dinâmica é intensificada com a introdução de inovações tecnológicas e organizacionais, flexibilização e reestruturação no mundo do trabalho, expressando desigualdades sociais renovadas que tendem a modificar a divisão social do trabalho e particularmente uma de suas dimensões: a divisão do trabalho entre homens e mulheres.

A partir da análise do processo atual de intensa reorganização da produção, este estudo propõe questionar a construção das diferenças e das desigualdades no trabalho nas relações de gênero no setor da cons-

* Professora doutora do DSS - Universidade Federal de Sergipe, Coordenadora do Núcleo de Estudos e Pesquisa Interdisciplinares sobre a Mulher e Relações de Gênero NEPIMG - UFS, pesquisadora associada da Rede Feminista Norte, Nordeste de Estudos e Pesquisas sobre a Mulher e Relaçōes de Gênero - REDOR. e-mail: helenacruz@uol.com.br. 
trução civil no espaço e tempo de Sergipe. Pergunta-se: qual o teor dessas mudanças? Elas configuram uma inserção essencialmente positiva da mão-de-obra feminina ou recriam padrões de discriminação, desigualdade sociais, uma nova divisão sexual do trabalho?

A abordagem destas questões tem se revelado enriquecedora, por incorporar novos enfoques teórico-metodológicos e aprofundar a compreensão de categorias importantes, relacionadas com educação, qualificação e gênero ${ }^{1}$. De fato, nesses últimos anos, a questão do trabalho tem sido analisada em diferentes instâncias definidoras das relações interpessoais, tais como as categorias empíricas que resultaram da necessidade de compreender uma realidade complexa.

Como pressuposto básico a investigação se respalda na idéia de que o trabalho concebido, tanto em sua positividade de trabalho humano em geral quanto em sua dimensão degradante enfatizada nas sociedades de classes, permanece central e não periférico ${ }^{2}$, como um princípio educativo que rege as relações homem/natureza e homem/homem, porque é a fonte principal de conhecimento, riqueza e bem-estar social, diante do avanço das forças produtivas e das novas formas de organização do trabalho, sobretudo por inspirar a crítica ao trabalho capitalista. Também a pesquisa orienta-se pelo princípio fundamental de que as relações sociais são dialeticamente construídas por meio de diferentes processos históricos, permitindo desvendar as representações dos trabalhadores da construção civil.

A ênfase recaiu sobre a metodologia qualitativa para integrar o sujeito e a história, os aspectos quantitativo/qualitativo, o geral e o particular, o coletivo e o individual, o objetivo e o subjetivo. A opção pelo tipo de "estudo de casos organizacionais" realizado nas empresas Norcon,

1 O estudo aprofunda linhas de pesquisa do Núcleo de Estudos de Gênero da UFS, este último integrado à Rede Norte e Nordeste de Estudos e Pesquisas sobre a Mulher e Relações de Gênero (REDOR), do Grupo de Pesquisa do $\mathrm{CNPq}$, integrando diferentes perspectivas teórico-metodológicas.

2 A este respeito, C. OFFE (1989), em sua tese, polemiza ao ver a necessidade de reconsiderar a estrutura de conceitos sociais, "questionando centralidade do conceito de sociedade do trabalho", tanto em sua configuração objetiva quanto subjetiva, observando-se "um declínio da ética do trabalho". 
do paradigma de produção baseado no modelo taylorista/fordista para os novos modelos produtivos. Esse processo poderia ser sintetizado da seguinte forma: passagem de uma produção de massa padronizada para uma produção de massa em pequena escala, mas flexível, conhecida como "especialização/acumulação flexível" que apresenta três grandes características: as inovações tecnológicas trazidas pela informática, microeletrônica e pela descoberta de novos materiais possibilitam o aumento da produtividade e maior flexibilidade dos processos produtivos. A eletrônica amplia o desenvolvimento da automação, da robótica, da telemática e determina outras formas de utilização da força de trabalho que implicam em ressignificações nas relações de poder. A segunda característica se expressa pela mudança das relações entre as empresas, por meio das quais se dissemina a prática da terceirização, que concentra os esforços naquelas atividades sobre as quais a empresa detém evidentes vantagens competitivas, desmembrando parte de suas outras atividades e passando a adquirir serviços e insumos de outras empresas, sejam elas nacionais ou não, expressando, desta forma, uma tendência de descentralização empresarial e desverticalização industrial.

A última característica se refere ao advento de novos processos organizacionais na produção, principalmente uma maior coordenação entre as várias áreas e departamentos e no trabalho interno das empresas visando obter eficiência, aumentar sua competitividade, conquistax novos mercados, reduzir custos e melhorar a qualidade dos produtos, assim como a diminuição de níveis hierárquicos com o objetivo de agilizar a tomada de decisões. Essa dinâmica tem possibilitado uma maior participação do trabalhador na gestão do processo de produção.

Nessa linha de reflexão são relevantes as contribuições apresentadas por Coriat (1982) e Vargas (1985), consideradas fundamentais para a compreensão dos processos de produção e organização do trabalho. Para a análise da categoria qualificação sobretudo Braverman (1987), apoiado no marxismo, inicia o debate em torno da tese da desqualificação e da degradação do trabalho na sociedade, chamando a atenção sobre as noções de qualificação/desqualificação e requalificação da força de trabalho no processo de produção taylorista/fordista industrial. 
A DIFICIL EQŨIDADE DE GÊNERO NO COTIDIANO DO TRABALHO NA CONSTRUÇĀO CIVIL

tências e saberes sociais, percebe-se uma requalificação e reprofissionalização dos trabalhadores, assim como a extinção de alguns postos de trabalho e o surgimento de outros. Do trabalhador é exigida aptidão para trabalhar em equipe, para se adaptar às mudanças no tipo de atividade que irá desempenhar, para exercer liderança, etc, ocorrendo, ao mesmo tempo, a obsolescência de algumas funções, o desenvolvimento de outras e mudanças nas relações sindicais. Contudo, essas mudanças não ocorrem de maneira homogênea, nem mesmo dentro de uma mesma firma.

Para as análises das categorias trabalho/educação/qualificação, algumas recorrências são utilizadas como obrigatórias na literatura internacional por autores consagrados, sob a perspectiva históricocrítica fundamentada em interlocuções como Habermas $(1985,1987)$, Baethge (1994) e Markert (1994) para a compreensão das relaçōes de gênero como desenvolvimento de subjetividades/identidades. As argumentações foram ampliadas com contribuições de diferentes teóricos do cenário nacional como: Salm (1980), Gorz (1990), Frigotto (1984), Kuenzer (1985 e 1987), Machado (1982 e 1989), Paiva (1995), dentre outros.

Destarte, as transformações do capitalismo e a adoção de novos modelos produtivos reafirmam as tendências mais gerais que vêm se manifestando em quase todos os setores da atividade econômica presente no país, impulsionadas pela busca incessante de "acumulação flexível" (Harvey, 2002). As conseqüências dessas transformações sobre o mundo do trabalho, embora diferentes na sua forma de manifestação, estão intrinsecamente relacionadas. De um lado, observa-se que o crescimento econômico não tem conseguido gerar empregos no ritmo necessário para absorver a população que ingressa no mercado de trabalho assalariado regulamentado e, mais do que isso, os avanços tecnológicos têm destruído diversos postos de trabalho, principalmente os intermediários, que não mais voltarão a ser criados. De outro lado, observa-se uma polarização dos postos de trabalho em "bons" e "maus" empregos, sendo que os primeiros tendem a ser destinados aos trabalhadores que preenchem melhor as novas exigências de mercado, especialmente quanto ao maior grau de escolaridade, na medida em que este atributo con- 
fere ao trabalhador a capacidade de reciclar seus conhecimentos e, com isso, manter seu emprego ou estar apto a disputar, com maiores chances, novas oportunidades de trabalho.

As questões relativas à participação e atitudes da força de trabalho feminina são ressaltadas neste trabalho, tendo por base os papéis de gênero e as determinações econômicas, sociais e culturais. Nessa linha de argumentação, aventou-se a hipótese de que os processos modernizantes conformam os espaços da cidadania, caracterizando relações de trabalho definidoras do lugar da mulher normatizado por formas de disciplinarização e de controle social com características patriarcais subjacentes nas representações sobre o trabalho.

\section{GÊNERO E TRABALHO}

É importante ressaltar que o aumento da participação da mulher na força de trabalho é uma das mais notáveis transformações da estrutura social nas últimas décadas, em todas as sociedades industriais desenvolvidas. Esse aumento é devido a uma complexa interação de mudanças econômicas, técnicas e demográficas, as quais, por sua vez, parecem estar intimamente conectadas a uma mudança sócio-cultural em direção ao "individualismo, igualdade de oportunidades e uma nova ordem básica de papel de gênero" (Scott, 1990), aqui entendido como as características de masculinidade e de feminilidade definidas socialmente. No entanto, existem diferenças significativas na extensão deste aumento, como também nas atitudes relativas à participação da mulher na força de trabalho em vários setores da sociedade.

$\mathrm{Na}$ abordagem do trabalho/gênero, busca-se uma maior interlocução com posições de vários autores que teorizam sobre a questão (M. Cas* tro, 1992; Castro, 1987, 1992, 1994; Kergoat, 1987), chamando a atenção para a construção de identidades, diferenças e igualdades na qualificação de homens e mulheres. Marx e Engels (1982), priorizando a dimensão histórica da vida, propõem que as formas humanas de comportamento, longe de se constituírem em atributos naturais, são construídas ao longo de um processo no qual as relações de trabalho assumem dimensão privilegiada. A consciência surge, então, não como algo 
inato, desde sempre existente no homem e imutável. "Nãoé a consciência que determina a vida, é a vida que determina a consciência" (p. 23).

No que se refere ao trabalho feminino, torna-se obrigatório o resgate da literatura com referência aos clássicos da temática, a exemplo de Safiotti (1992), Pena (1981), Abreu (1993), Hirata (1996), Kergoat (1987), SouzaLobo (1991) eAbramo (1995) entre outros que buscam atualizar a reflexão. Os estudos apresentam como ponto comum: as barreiras encontradas por mulheres, no mercado de trabalho, resultantes de dimensões sociais e culturais de uma socialização vinculada a uma noção de patriarcado (relações autoritárias atribuídas à estrutura familiar) e a um conjunto de relaçōes hierárquicas que diferenciam a posição social da mulher em relação ao homem. Admitindo-se os aspectos de uma divisão social entre os sexos, Castro e Guimarães (1987) enfatizam que esses processos de diferenciação se aprofundaram com a complexidade crescente da sociedade, com a sua especialização e ainda com o aumento da produtividade.

Tentando fazer uma articulação da questão de gênero com classe, Safiotti (1992:207) diz: "quando levadas em consideração, as contradições de gênero podem elevar o nível de consciência de classe, já que as fraturas desta não significam poros vazios, mas fissuras recheadas de desigualdades entre homens e mulheres...". Mais adiante ela acrescenta: "enquanto as contradições da sociedade não forem superadas haverá distintas perspectivas de classe, de raça e de gênero". Para alguns, ao tentar reafirmar a articulação entre gênero e classe social, Saffioti termina afirmando a presença de estratificação em gênero. Apesar das contribuições significativas que a problemática da divisão do trabalho trouxe para a análise sobre o trabalho feminino, parte da produção especialmente brasileira que problematizou a divisão sexual do trabalho, o fez ainda relacionando divisão sexual do trabalho e patriarcado.

Para Souza-Lobo (1991:200):

as relações entre homens e mulheres são vividas e pensadas enquanto relações entre o que é definido como masculino e feminino - os gêneros. Nesse sentido, a divisão sexual do trabalho é um dos muitos lócus das relações de gênero (...) Abrindo espaço para se pensar as novas questões que preocupam a sociologia do trabalho: as "metamorfoses" do traba- 
lho e o seu questionamento, a subjetividade no trabalho, e as identidades no trabalho, o problema de igualdades e diferenças e as formas contemporâneas de gestão e de políticas sociais.

De acordo com essa autora a formulação do patriarcado, mesmo relativizada por diferenciações históricas, permanece no quadro de referências a uma estrutura determinante, fundada em bases materiais. As relações patriarcais são compreendidas por uma dialética objetiva e subjetiva de formas interativas, tal como problematizadas através da teoria de educação histórico-materialista, no que se refere às condições objetivas e subjetivas da identidade/subjetividade de trabalhadores. No conjunto de práticas de representações os trabalhadores constroem identidades de gênero vivendo uma diversidade de experiências de negação e de afirmação: desde a oportunidade de adquirir qualificação até o reconhecimento de seu próprio trabalho.

A abordagem de gênero desvela o processo de construção de identidades de homens e mulheres mergulhados em um contexto histórico na posição social em que estão inseridos, reflete valores, crenças; enfim, aspectos cognitivos, afetivos e emocionais engendrados pelo tempo/espaço geográfico. $\mathrm{O}$ estudo destacou a realidade das mulheres na indústria da construção civil, para desvendar as relações de poder e hierarquia, os obstáculos e oportunidades por elas encontrados no cotidiano do trabalho influenciando sobremaneira o subjetivo e o imaginário destas mulheres.

São analogamente referidos significados de situações de formação para a regulação nas relações de trabalho feminino ou para a participação no consentimento (no jogo, adaptação, submissão), com regras e normas, esculpidos em vários âmbitos institucionais como a família, escola, meios de comunicação, sindicatos, estado, etc. Nessa situação, com freqüência, as mulheres são deixadas sem as defesas materiais da qualificação. Ao mesmo tempo, suas defesas ideológicas e coletivas são solapadas. Não se pode esquecer que os processos de reprodução nas esferas pública e privada são altamente mediadores na construção das representações sociais de gênero/classe/raça, estruturadas nas experiências cotidianas no mercado "interno" do trabalho, particularmente na indústria da construção civil. 
O conhecimento dos processos sociais, inclusive o esclarecimento das experiências de trabalhadoras(es), se faz concreto pelo estudo das representações sociais por ser um caminho possível para atingir tal propósito, na medida em que investiga justamente como se forma e como funciona o sistema de referência que utilizamos para desmistificar pessoas e grupos e para interpretar os acontecimentos da realidade cotidiana. Assim, a concepção de representação social explicitada por Jodelet (1989) abrange elementos específicos esclarecedores de uma forma de conhecimento, o saber do senso comum, cujos conteúdos se manifestam na operação de processos generativos e funcionais socialmente marcados. De maneira mais ampla, ela designa uma forma de pensamento social.

É importante destacar que o processo de modernização da produção no Brasil e em Sergipe vem se delineando, ainda que de forma incipiente, desde meados da década de 1980 , em resposta à crise econômica. Contudo, é a partir da década de 1990, com o aprofundamento da recessão e com a política de abertura comercial, que as empresas começam a se preocupar em tornarem-se mais competitivas e a melhorar a qualidade de seus produtos. As conseqüências desse processo sobre o nível de emprego têm sido evidenciadas por vários estudos, conforme dados da IBGE/ PNAD para o período de 1988-1993 e para os anos de 1994 e $1995 . \mathrm{Na}$ indústria, o nível de emprego declinou desde o começo dos anos 1990, mesmo com a retomada do crescimento da produção industrial a partir de 1993.

É nesse contexto da reestruturação produtiva que o setor da construção civil sofre transformaçōes tanto na sua esfera produtiva como na gestão das relações de trabalho, necessitando, cada vez mais, de grande flexibilidade para o gerenciamento de decisôes, em decorrência da natureza e especificidade das atividades que exerce e dos serviços que produz, principalmente em economias com elevadas taxas de inflação, como é o caso da economia brasileira do início dos anos 1980 até meados de 1994.

A Indústria da Construção Civil: principais características do setor.

A indústria da construção civil é caracterizada por um conjunto bastante diverso de atividades, que vai da produção tipo fabril (construção 
de prédios, pontes, ferrovias, etc.) à terciária, de prestação de serviços (consultoria, projetos, etc) e quase bancárias, o que dificulta uma abordagem conjunta de todo o setor, demonstrando o grau de complexidade que o envolve. Diante da diversidade dessa indústria, a mesma está dividida em três grandes áreas de atuação: o subsetor da Construção Pesada - construção de infra-estrutura viária, urbana e industrial, obras de arte e saneamento; o subsetor da Montagem Industrial - montagem de estruturas para a instalação de indústrias, de sistemas de geração, transmissão e distribuição de energia elétrica, de sistemas de telecomunicações e de exploração de recursos naturais; e o subsetor de Edificações - construção de edifícios residenciais, comerciais, de serviços e institucionais, conjuntos habitacionais e obras em fase de processo edificativo. Esse subsetor é considerado um dos mais importantes da Construção Civil, por apresentar um maior número de empresas (71\%) e de empregados (72\%) formais (DIEESE, 2001).

Ainda no subsetor de edificações, responsável pelo processo de urbanização das cidades, destacado neste estudo, encontra-se outra subdivisão: de grande, médio e pequeno porte, diferenciada pelo número de trabalhadores e pela tecnologia utilizada no seu processo de produção. A importância da Indústria de Construção Civil como grande empregador de mão-de-obra tem respaldo nas ações governamentais de valorização desse setor na geração de novos empregos ${ }^{3}$, isso porque ele dá apoio a outras atividades econômicas e sociais. A construção se caracteriza pela utilização de uma produção mecanizada e não industrializada, com o uso intensivo da força de trabalho presente em todos os subsetores, independente do porte da empresa ou da tecnologia utilizada, uma vez que a própria natureza do processo produtivo impede o uso de equipamentos, com exceção das tarefas mais pesadas. Apenas as grandes empresas têm o poder de aquisição de inovações tecnológicas. Afirma-se que para cada cem postos de trabalhos diretos gerados no setor, outros 285 são abertos nos demais setores do chamado macro setor da Construção Civil.

3 A Construção Civil foi valorizada no Programa de Estratégia de Desenvolvimento (1963/70), nas Metas e Bases para Açāo do Governo (1970), no I Plano Nacional de Desenvolvimento (1972/74) e na Implementação do Plano Nacional de Habitação (ARAÚJO, 2001). 
É ainda notável o grande desempenho das empresas no que se refere à qualidade dos serviços, daí o esforço das grandes construtoras na aquisição de títulos de controle/gestão de qualidade total, como é o caso da ISO 9001. Assim, ao utilizar inovações, à indústria de construção cabe a função de oferecer maior flexibilidade aos projetos, aparecendo como possibilidades que servem a determinados nichos de construção. Além de permitir alcançar melhores padrões de qualidade e acelerar alguns procedimentos da construção, o processo de reestruturação produtiva, induzido principalmente por um aumento da instabilidade econômica, visa à integração da produção e maior flexibilidade na decisão sobre o que, quanto e onde produzir, acirra a competição e a escalada de conflitos entre empresas e trabalhadores.

O modelo flexível, que articula um desenvolvimento tecnológico e novas formas de gestão do trabalho, introduz modificações substanciais nos canteiros de obra representados pela utilização de estruturas pré-fabricadas e/ou pré-moldadas, ou à total substituição de materiais, objetivando minimizar custos com materiais, encargos sociais e com a mão-de-obra, intensificando-se a terceirização. Contudo, esse processo não é algo novo no setor, aprofundado agora com a reestruturação, retirando das empresas a responsabilidade dos custos sociais com o trabalhador, enquanto que esses ficam à margem dos direitos sociais da Previdência, pois são trabalhadores de "empreitadas", conhecidos como "subempreitada/subcobtratação", que nada mais é do que a contratação de empresas menores que participam do processo produtivo na realização de etapas segmentadas e distintas da construção. Portanto, é comum a presença de trabalhadores sem vínculos empregatícios, contribuindo para o aumento da taxa de rotatividade em decorrência do processo de recrutamento/seleção realizado, favorecendo o desligamento dos trabalhadores após um pequeno espaço de tempo. Esse processo possibilita a extinção do posto de trabalho após a conclusão da obra.

De fato, a dinâmica de funcionamento da indústria de construção acaba provocando altíssimas taxas de rotatividade, tornando-se esta uma característica básica do setor. Os trabalhadores apresentam algumas particularidades entre outras categorias profissionais, isso 
porque têm relações de trabalho das mais precárias em relação aos diversos ramos da atividade econômica. Outra característica da mãode-obra é que apesar da Construção Civil ocupar mais de $4.700 \mathrm{mil}$ pessoas, somente ( $20,1 \%$ do total) são empregados com carteira profissional assinada. Os demais ocupados são: empregados sem carteira assinada ( $30,9 \%$ do total), conta própria ( $41,1 \%$ do total) e trabalhadores ocupados na construção de suas próprias casas ou sem remuneração ( $3,6 \%$ do total). Outro indicador que caracteriza a mãode-obra da construção civil é a jornada de trabalho, uma vez que $50 \%$ deles excedem as 44 horas semanais e $22 \%$ se prolongam para mais de 49 horas. Mas pode acontecer a jornada parcial, quando o trabalhador se ocupa de uma jornada inferior a 40 horas, o que significa que as horas trabalhadas não vão atender suas necessidades devido à falta de ocupações em tempo integral. Vale ressaltar que a remuneração dos trabalhadores apresentou uma ligeira alteração, pois os que recebiam acima de 5 salários mínimos superaram os que recebiam de 1 a 2 salários mínimos; mesmo assim a remuneração média está muito aquém de atender às necessidades mínimas de um trabalhador e sua família. A origem dessa força de trabalho está, em sua maioria, na zona rural ou em outras regiões do país, ou nas periferias das cidades; apresentam um baixo nível de instrução e qualificação profissional: $64,8 \%$ estudaram até a $4^{a}$ série do ensino fundamental, sendo que mais da metade é analfabeta ou tem a $4^{\mathrm{a}}$ série incompleta (IBGE, 1997).

A Construção em Sergipe - como no Brasil ocupa um importante papel na economia sergipana, tanto pela grande absorção de mão-deobra como na urbanização das cidades, a exemplo de Aracaju, onde se percebe a construção de bairros totalmente verticalizados. Apesar do número considerável de trabalhadores, ainda é grande o desemprego na construção civil em Sergipe, além de que o salário é o menor em todo o Brasil (Informação coletada com o Presidente do Sindicato dos Trabalhadores da Construção Civil em Sergipe).

Nos últimos anos, observa-se, no país, um crescimento considerável da participação de mulheres no mercado de trabalho sergipano. Dados a esse respeito constatam que a ocupação de mulheres nos diversos 
A DIF́́CIL EQUUIDADE DE GÊNERO NO COTIDIANO dO TRABALHO NA CONSTRUÇĀO CIVIL

setores econômicos se apresenta diferenciada daquela relacionada ao conjunto da população ativa (Cruz, 1999).

Em Sergipe, a exploração salarial da mulher é mais concentrada na agricultura, no comércio e na zona rural; de modo geral, os salários pagos são inferiores aos das zonas urbanas. A mulher sergipana, em sua maioria, recebe salários com valores $50 \%$ menores do que os dos homens no desempenho de funções idênticas, assim diz pesquisa feita em Sergipe, na qual também se constatou que os representantes do sexo masculino conseguem $58 \%$ das vagas de empregos contra $42 \%$ das mulheres. Esses números foram retirados de uma amostragem de 747.427 pessoas entrevistadas (IBGE, 1997). Ademais, 20\% das mulheres integrantes da população economicamente ativa no Brasil desenvolvem atividades na área de prestação de serviços, ou seja, elas são predominantes em atividades no setor terciário, concentradas na área de serviços, particularmente nos serviços pessoais (algo que representa $33 \%$ do total de mulheres ativas profissionalmente em 1984).

$\mathrm{Na}$ área de serviços as colocações profissionais dizem respeito, principalmente àquelas de baixo status social, como as de empregadas domésticas, costureiras, lavadeiras, etc, profissões que exigem pouca instrução e mínima qualificação profissional, ao contrário das colocações na área social (DIEESE, 2001). Contudo, uma importante mudança estrutural vem ocorrendo nas últimas décadas: é o aumento das oportunidades educacionais para a mulher; 1980/2000, a discriminação da mulher na educação parece superada. Nas últimas décadas, apesar da considerável participação feminina no mercado de trabalho, observa-se que existem diferenças significativas nesse aumento, como também nas atitudes relativas a essa participação. Verifica-se, entretanto, que não se dispõe de dados mais aprofundados sobre as condições em que vêm ocorrendo esse processo no setor da construção civil, principalmente focalizando as dificuldades encontradas por elas ao se inserirem nesse setor de trabalho tradicionalmente masculino. Este trabalho destaca, especificamente, a situação da mulher e as oportunidades abertas para elas no setor da cons* trução civil. 


\section{ALGUNS RESULTADOS}

A reestruturação produtiva gerou expressiva mudança tecnológica e introduziu métodos renovadores na organização do trabalho, colocando demandas de novos perfís de qualificação para os trabalhadores, visando obter maior produtividade e agilidade na realização das tarefas.

Destarte, a gestão tradicional da força de trabalho centrada na estrutura de poder representada pela hierarquia dos ofícios sobrevive, através de inúmeras práticas difundidas no setor da construção civil. A gerência de obras continua a adotar políticas de pessoal e de relações de trabalho taylorizadas, pautadas em modelos autoritários, na improvisação e na tentativa de imposição dos controladores da produção sobre o trabalho operário. Inúmeros conflitos por eles vivenciados cotidianamente expressam a desigualdade nas ações dos gerentes dos canteiros, responsáveis pela implementação das medidas que afetam diretamente as relações de trabalho e a própria reprodução dos operários. Assim, houve um aumento considerável do número de pessoas desempregadas, inclusive se mantendo muito tempo nessa situação, decorrente de uma redução relativa ou absoluta de empregos estáveis ou permanentes nas empresas e da maior subcontratação de trabalhadores temporários, em tempo determinado, eventuais, em tempo parcial, etc. Essas mudanças ratificam "a atual tendência dos mercados de trabalho em reduzir o número de trabalhadores 'centrais' e empregar cada vez mais uma força de trabalho que entra facilmente e é demitida sem custos quando as coisas ficam ruins" (Harvey, 2002:144).

Nos casos estudados as três empresas integram o universo de 2.085 trabalhadores, composto por $93 \%$ de homens e apenas $7 \%$ de mulheres, confirmando a tese da masculinização do setor da construção civil. Assim, a modernização nas empresas se mostra desfavorável às mulheres, refletindo condicionantes sócio-culturais, relações de poder/classe/ gênero que perpassam a sociedade. A Norcon emprega um maior número de trabalhadores $(48,6 \%)$, seguida pela Celi, com $34,4 \%$ e Cosil com $17 \%$. Os dados informam um maior número de trabalhadores(as) na construção civil inseridos na faixa etária de 31-40 anos, representando $34,8 \%$ de homens e $39,5 \%$ de mulheres; isso revela a preferência por 
A DIFÍCIL EQŨIDADE DE GÊNERO NO COTIDIANO dO TRABALHO NA CONSTRUÇĀO CIVIL

trabalhadores jovens, particularmente, mulheres solteiras e sem filhos $(62,8 \%)$ para o trabalho na construção. Contudo, um outro fator significativo é a incidência (11,7\%) de homens acima de 50 anos de idade no canteiro de obras. Nesses espaços se encontram apenas $147(0,7 \%)$ mulheres, sugerindo que a concentração do saber, da experiência, da estrutura de ofícios, do poder-técnico social desenvolve diferenciações no processo de inserção ao trabalho.

As engenheiras, por exemplo, têm dificuldade de mostrar sua competência técnica com autonomia: "existe desconfiança quanto à competência técnica das mulheres para supervisionar, acompanhar a construção de um edifício". É como se o domínio da técnica fosse exclusivamente masculino. Freqüentemente elas são supervisionadas por um engenheiro. A esse respeito, observa-se divergência na visão das gerências sobre os avanços obtidos por mulheres. Eles acreditam haver um período de transição que hoje foi vencido:

eu tenho hoje engenheiras trabalhando nas obras, comandando grupos de homens às vezes... e elas têm a mesma autoridade que um homem pode ter, porque as pessoas hoje são selecionadas não mais tendo como parâmetro o sexo, e sim, a capacidade delas... de desenvolver as atividades exigidas pela empresa. O que acontece é que as profissões técnicas são tradicionalmente masculinas: engenheiroscivis normalmente são mais homens do que mulheres nesse mercado. Mesmo assim as mulheres conseguiram o espaço delas, entram como estagiárias, técnicos de obra, mulheres trabalhando diretamente com homens; elas conseguem mostrar sua capacidade e impor sua autoridade diante do grupo masculino.

As estatísticas descobrem a segmentação/divisão sexual do trabalho na construção civil, nos setores, ocupações e qualificações fortalecendo a exclusão. Nas três empresas as mulheres se concentram nos cargos administrativos (38,8\%), comparativamente aos homens (4\%). Enquanto nas engenharias, cargos considerados masculinos e de muito prestígio, encontram-se 32 homens (10,2\%), significando maior poder, autonomia, responsabilidade e iniciativa no exercício dessa função. Neste posto, as 
mulheres são apenas $15(1,7 \%)$, observando-se portanto, forte assimetria e desequilíbrio das forças em jogo. Conquanto na empresa Celi a presença da mulher seja mais reduzida (6\%), elas se concentram nos cargos de engenheiras e em menor proporção nos cargos operacionais e de menor prestígio. Na empresa Norcon, as mulheres representam $8 \%$ dos trabalhadores, e estão mais presentes nos canteiros de obras, na função de servente e em atividades de acabamento, rejuntamento e limpeza.

Enquanto na Cosil, as mulheres representam $7 \%$ e desempenham funções ligadas à administração da empresa: elaboração de projetos, orçamentos e finanças. As atividades de produção direta, elaboração do produto fim da empresa no canteiro de obras, são responsabilidade de peões e de engenheiros homens. As qualificações técnicas de mulheres por si so não são suficientes para sua inserção em atividades operacionais. As entrevistadas ressaltam que "a ausência de mulheres nos canteiros de obras na Cosil, deve-se ao caráter de proteção à mulher, para evitar desrespeito por parte dos "peões", haja vista que a mão-de-obra predominante no canteiro de obras é rústica e desqualificada".

Assim, as restrições socioculturais, os estereótipos de papéis adequados a homens e mulheres, estruturam diferenças, tratamentos desiguais em termos de contratos e salários. Uma marcação histórica e socialmente construída define lugares de trabalho adequados ao homem e a mulher. A inserção das mulheres no trabalho parece então, fortemente definida por suas qualidades/qualificações sociais ou tácitas, também chamadas "habilidades femininas", por atributos das tarefas e de seus executores, conforme ilustrado no exemplo: "a gente adota o trabalho feminino por ser mais detalhado, mais cuidadoso; elas apresentam mais minúcia e perfeição no trabalho e em geral, se sobressaem e as pessoas gostam do trabalho feminino. As mulheres sempre são contratadas em número menor".

Tais habilidades exercitadas pelas mulheres no âmbito privado da família são transferidas para o trabalho produtivo, integrando-se o trabalho informal e o formal. As atividades que demandam agilidade motora, atenção, cuidado e paciência são ratificadas perante o público externo, legitimando-se a identidade pela carteira profissional, em ocupações que 
não exigem elevada qualificação. Por outro lado, as habilidades comportamentais que integram o "saber-ser", capacidades relacionais (consideradas qualidades e não qualificações quando se trata de mãode-obra feminina), são valorizadas para o trabalho administrativo, para a relação de serviço no qual as mulheres apresentam escolaridade mais elevada. De qualquer forma, elas estão ocupando os espaços tidos como "femininos", reflexo da divisão social e sexual do trabalho.

A baixa escolaridade dos trabalhadores nas empresas reafirma uma característica peculiar do setor da construção civil. O nível de ensino fundamental ${ }^{4}$ completo ou incompleto $(90,2 \%)$ é dominante. A Norcon proporcionalmente apresenta menor número de trabalhadores com o nível superior se comparada à Celi. Já o processo seletivo adotado na Cosil, de antemão exclui o trabalhador analfabeto, caracterizado como mão-de-obra migrante do interior do Estado. Contudo, nesse ponto, as mulheres encontram-se em situação mais vantajosa. Parece, então, que elas já se introduzem no mercado de trabalho com maior escolaridade, porque foram submetidas a um longo processo de formação, requisito inclusive para a sua inserção no mercado de trabalho formal. Elas apresentam o ensino fundamental completo ou incompleto $(36 \%)$ e o ensino superior completo ou incompleto $(28 \%)$, relativamente aos homens $(3,1 \%)$.

As trabalhadoras almejam diversificar, ampliar sua formação no sentido de obter vantagens nos ambientes de trabalho e assim, reduzir os processos de exclusão. Contudo, elas não são estimuladas a participar de treinamentos técnicos e ressentem-se de escassas oportunidades oferecidas pelas empresas.

Ademais, os papéis desempenhados por mulheres na família descobrem a precariedade das relações sociais e a dupla jornada de trabalho. Elas utilizam estratégias para conciliar às atividades econômicas, o trabalho produtivo com as responsabilidades domésticas, estas últimas exercidas, por elas, com exclusividade (administração da casa, educação dos filhos, etc). Pesquisas recentes (Hirata, 2002)

\footnotetext{
4 O Ensino Fundamental está representando pelo antigo primário.
} 
efetuadas no Brasil, junto a trabalhadores e trabalhadoras industriais de grandes centros urbanos mostram que houve modificações na repartição do trabalho doméstico, segundo a fala dos entrevistados, com maior participação dos homens em diferentes tarefas do que o que mostrou pesquisa realizada anteriormente. Essa mudança parece ter relação direta com a inserção das mulheres no mercado de trabalho e sua forte participação em atividades profissionais fora do domicílio. Entretanto, ela parece ter um caráter restrito e tópico e não atinge o âmbito das responsabilidades domésticas, que continuam a ser atribuídas exclusivamente às mulheres. Mesmo contribuindo com o seu trabalho para o orçamento familiar freqüentemente, as mulheres não possuem autonomia de decisão quanto à prioridade dos seus gastos. As relações sociais criam e recriam relações de poder desvantajosas para elas, tanto no âmbito privado quanto no âmbito público.

$\mathrm{O}$ meu marido nunca gostou que eu trabalhasse aqui, porque os homens desrespeitam as mulheres. Ele diz: 'tá bom de você arrumar alguma coisa melhor!' Mas ele sempre deu valor ao meu trabalho.

Nem todos os homens respeitam as mulheres, se eles bulir, disser lorota, a gente não dá ousadia, atenção a eles, senão começam a deformar as coisas. Aqui não é um bom emprego para mulher porque os homens, realmente, não respeitam. Eles acham porque somos mulheres tem que fazerem o que querem!

As mulheres se preocupam em manter uma certa ética no trabalho, em espaços tradicionalmente masculinos em que a cultura patriarcal se mostra enraizada. Elas utilizam, no cotidiano, estratégias de mudança para a permanência nos ambientes de trabalho e para fazer valer o respeito às diferenças, vencendo os estereótipos de papéis em relação às determinações biológicas. 


\section{CONSIDERAÇÕES FINAIS}

Um conjunto de tendências - potencialmente contraditórias - no mundo do trabalho pode, na atualidade, melhorar ou aprofundar as desigualdades entre segmentos vulneráveis da força de trabalho, dificultando sua participação política dentro do quadro de desenvolvimento do capitalismo.

O setor da construção civil apresenta peculiaridades que merecem muita atenção dos estudiosos dos padrões de gestão e das relações de trabalho com recorte de gênero. Tudo parece indicar que ele está vivenciando um processo de transição lenta para um novo modelo de gestão e organização do trabalho, no qual duas propostas estão em disputa: de um lado, a política tradicional de absorção de mão-de-obra, tendo como eixo a dilapidação da força de trabalho, e, de outro, uma nova política interessada nos novos princípios da produção (integração e flexibilidade) e na fixação dos trabalhadores na empresa, adotando critérios de qualidade e produtividade que se difundem por todo o parque industrial.

Nesse processo de transição, contudo, os principais perdedores são os trabalhadores com maior capital humano específico e pouco capital humano geral, os quais sofrem com a deterioração da qualidade e do rendimento do trabalho causados pela depreciação acelerada e, em alguns casos, irreversível de seu capital humano, diminuindo e/ou piorando a qualidade de sua reinserção no mercado de trabalho e/ou em atividades relacionadas ao auto-emprego.

Observa-se que a condição de boa parte dos postos de trabalho tem se deteriorado por dois motivos: primeiro, pelo aumento do emprego em alguns subsetores de serviços nos quais, na maioria dos casos, as relações de trabalho são "precárias"; isto é, o processo de contratação situase à margem de vários direitos trabalhistas e quase sempre com salários menores. $O$ segundo motivo se refere ao aumento da taxa de desemprego aberto, que pode ser percebida como desemprego estrutural. Apesar dos condicionantes externos atribuídos ao inevitável processo de globalização, compreende-se que a política econômica interna do país ainda pode exercer um papel importante na manutenção do nível do 
emprego. E é dentro dessas transformações na sociedade, em função do processo produtivo (trabalho assalariado), que a mulher está ganhando espaço no mesmo, conseguindo sair da "invisibilidade social" e da esfera reprodutiva (trabalho doméstico). O espaço existencial da mulher se definia na mediação do espaço domiciliar, contudo a expressiva ampliação de sua participação no espaço público colore, com novas tintas, essa forma de participação.

Nesse sentido, os dados aqui apresentados refletem como homens e mulheres são afetados diferentemente por processos de desenvolvimento e modernização e como se comportam produtivamente frente as condições que a sociedade do século XXI lhes oferece. Ou, por outra, como a lógica da reprodução social atua de forma diferente de acordo com a categoria a que pertence cada fração social. Assim, as identidades são múltiplas e abarcam um amplo espectro de realização, circunscrita pelos atributos de gênero: o estado civil, o número de filhos condicionam fortemente a inserção e permanência das mulheres nesse mercado de trabalho interno, isso porque os critérios de recrutamento favorecem as solteiras, jovens e sem filhos.

A análise comparativa das três empresas evidencia pontos comuns e divergentes no modo como as mulheres se identificam com o trabalho na construção civil. A construção de identidades, tem como foco cultura, tradição, memória, mercado e políticas que estruturam as identidades de gênero de homens e mulheres, mesclando elementos modernos e tradicionais. A reduzida participação de mulheres na profissão de engenheiras e técnicas ilustra o componente sociocultural inter-gênero, por meio da divisão profissional, na qual se considera as mulheres "mais aptas" a exercer determinadas ocupações e os homens "mais aptos" no exercício de outras. Esse dado responde totalmente pelo diferencial das condições sócio-econômicas encontradas entre homens e mulheres. Entretanto, na realidade, a diferença nos rendimentos em relação à posição na ocupação também acontece no interior da mesma classe ocupacional.

As condições de trabalho no setor questionam a necessidade de relativizar o papel da construção civil como "porta de entrada" para o emprego urbano, pois as precárias condições de contratação, os baixos 
salários e a humilhação/opressão existentes nas relações sociais não favorecem o desejo de fixação por parte dos operários. Neste sentido, ao invés de se conceber a indústria da construção civil como absorvedora de mão-de-obra desqualificada, excedente do campo, torna-se necessário considerar a rotatividade, por exemplo, imbricada com a política de recrutamento e demissão dos trabalhadores, como efeito da demanda de força de trabalho, devido às decisões político-financeiras do setor. Ademais, a demissão tem sido alvo de uma política altamente autoritária e arbitraria até os anos recentes.

Nos casos estudados, as mulheres apresentam escolaridade mais elevada, até porque na divisão sexual do trabalho elas estão em maior número nos cargos administrativos $(38,8 \%)$, nas ocupações de saúde e de apoio, e são pouco representadas nas ocupações de engenheiras, técnicas e nos cargos operacionais, caracterizados pelo trabalho pesado e considerados "masculinos". A questão do acesso da mulher à educação superior é considerada causa essencial da mudança normativa nas atitudes do papel de gênero. Isso porque a aquisição de instrução e a progressiva integração no mercado de trabalho possibilitam cada vez mais a ampliação de sua participação na esfera produtiva

No movimento do privado em direção ao público ela consegue romper com o modelo imaginário de mulher que se materializa em papel feminino no espaço reprodutivo; separação essa que se traduz numa divisão sexual do trabalho na esfera privada, ou seja, a designação da mulher para a reprodução foi sempre acompanhada por uma divisão sexual do trabalho datada desde o seu nascimento.

A construção da cidadania plena não pode, portanto, ser pensada sem que seja inserida na formulação de políticas públicas institucionais com o propósito central de redistribuir o poder e os bens materiais e simbólicos. Desse modo, o horizonte de gestão do trabalho na construção civil não parece estar adotando uma política de pessoal e de relações de trabalho afinada com o campo da democracia e da cidadania, deixando diversas interrogações a respeito deste desdobramento a médio e a longo prazos. 


\section{RESUMO}

O estudo objetivou desvendar as transformações condicionadas por processos de globalização, introdução de inovações tecnológicas e organizacionais, reestruturação e flexibilização do trabalho ocorridas na indústria da construção civil em Sergipe. A categoria gênero é utilizada como ferramenta/instrumento político privilegiado para a leitura do cotidiano, visando colocar em debate alguns dos espaços e relações onde o gênero se cons trói e se reproduz. Especial desta que é atribuído às representações dos trabalhadores e trabalhadoras sobre suas experiências nesse contexto de trabalho.

Palavras chave: gênero, construção civil, trabalho, qualificação.

\section{ABSTRACT}

This study intended to reveal the transformations conditioned by processes of globalization, introduction of technological and organizational enhancements, work restructuration and flexibilization occurred in the industry of civil construction in Sergipe. Gender category has been used as a privileged political tool/ instrument for the reading of daily, bringing to debate some of the spaces and relations where gender is built and reproduced. Emphasis is applied to the representations of male and female workers about their experiences in this labor environment.

Keywords: gender, civil construction, work, qualification. 


\section{REFERÊNCIAS BIBLIOGRÁFICAS}

ABRAMO, Laís W. Reconversión productiva, cambio tecnológico y empleo feminino na America Latina. Santiago/Chile: PRELAC/ OIT (mimeo), 1995.

ABREU, Alice, R. P. Mudanças tecnológicas e gênero no Brasil: (primeiras reflexões). São Paulo: Novos Estudos / CEPRAP, no. 35, 1993. BAETHGE, Martin. Trabalho, Socialização, Identidade. A crescente subjetivação do trabalho. In: MARKERT, W. (org.). Teorias da Educação e do Iluminismo: conceitos de trabalho e do sujeito. Rio de Janeiro: Tempo Brasileiro, 1994.

BRAVERMAN, Henry. Trabalho e capital monopolista: a degradação do trabalho no século XX. Rio de Janeiro: Zahar, 1987.

CASTRO, Mary Garcia. O conceito de gênero e as análises sobre mulher e trabalho: notas sobre impasses teóricos. In: Economia global, cidadania, democracia, gênero e família. Caderno CRH, Salvador, (17): 80-105, 1992.

CASTRO, Nadya A; GUIMARÃES, I. Brandão. Divisão sexual do trabalho, produção e reprodução. In: Relações de trabalho, relações de poder. Brasília: UNB, 1987.

CASTRO, Nadya Araújo. Organização do trabalho, qualificações e controle na indústria moderna. In: L.R.S. Machado; M. ANeves; G. Frigotto et al. Trabalho e educação. São Paulo, ANDE/ANPED. 1992.

CORIAT, Benjamins. El taller el cronometro. México: Siglo XXI, 1982.

CRUZ. Maria Helena Santana. Modernizaçao do trabalho e tradição: estudos de caso sobre as relações sociais de gênero em indústrias extrativas em Sergipe. Salvador, (mimeo). Tese (Doutorado em Educação), Faculdade de Educação UFBA, Universidade Federal da Bahia, 1999. 
DIEESE. A situação do trabalho no Brasil. "As mulheres no mercado de trabalho". São Paulo: Relatório DIEESE, 2001.

FRIGOTTO, Gaudêncio. A produtividade da escola improdutiva. São Paulo: Cortez Autores Associados, 1984.

GORZ, André. Crítica da divisão do trabalho. São Paulo: Martins Fontes, 1990.

HABERMAS, Jürgen. Conhecimento e interesse. Rio de Janeiro: Guanabara, 1987.

boa: Publicaçōes Dom Quieto, 1985.

HARVEY, David. Condição pós-moderna. São Paulo: Loyola, 2002.

HIRATA, Helena. Da polarização das qualificações ao modelo da competência. IN: Novas Tecnologias, Trabalho e Educação: um debate multidisciplinar. FERRETI, João Celso (Org.). Rio de Janeiro: Vozes, 1996.

. Reorganização da produção e transformações do trabalho: uma nova divisão sexual? In: BRUSCHINI, Cristina; UNBEBAUM, Sandra G. (orgs.). Gênero, Democracia e Sociedade Brasileira. São Paulo: FCC, 34. 2002, p. 341-355.

IBGE. Relatório do Censo Demográfico. PNAD. Dados de Censo de 1988, 1993, 1994, 1995.

JODELET, Denise. Representacións sociales: un domaine en expansion. In: Les Representacións Sociales. Paris: Presss Universitaire de France, 1989.

KERGOAT, Daníèle. Em defesa de uma sociologia das relações sociais: da análise crítica das categorias dominantes à elaboração de uma nova conceituação. In: KARTECHEVSCKY, André. O Sexo do Trabalho. 1987.

KUENZER, Acácia Z. A pedagogia da fábrica. As relações de produção e a educação do trabalhador. São Paulo: Cortez, 1985. 
. Educação e trabalho no Brasil. O Estado da questão. Brasília: REDUC/INEP, 1987.

MACHADO, L. R. de S. Educação e divisão social do trabalho. São Paulo: Cortez, 1982.

Politecnia escola unitária e trabalho. São Paulo: Cortez Autores Associados, 1989.

MARKERT, Werner. Teorias da educação do iluminismo. Conceitos de trabalho e do sujeito. Rio de Janeiro: Biblioteca Tempo Universitário, n. 95, 1994.

MARX, Karl. Manuscritos econômicos e filosóficos. 70. ed., Textos Filosófico, 1982.

PAIVA, Vanilda. Inovação tecnológica e qualificação. In: Educação \& Sociedade, n. 50, abril de 1995.

PENA, Valéria Junho. Mulheres e Trabalhadoras. Presença feminina na construção do sistema fabril. Rio de Janeiro: Vozes. 1981.

SAFFIOTI, Heleieth, I. B.A questão feminina em debate. Caderno do CEAS, n. 42, Salvador, 1992.

SALM, Claúdio. Escola e trabalho. São Paulo: Brasiliense, 1980.

SOUZA-LOBO, Elizabeth. A classe operária tem dois sexos. Trabalho/dominação e resistência. São Paulo: Brasiliense, 1991.

SCOTT, Joan. Gênero: uma categoria de análise histórica. In: Educação e Realidade. Porto Alegre, V. 16, n. 2, julho/dezembro, 1990.

VARGAS, Nilton. Gênese e Difusão do Taylorismo no Brasil. In: ANPOCS. Ciências Sociais hoje. Anuário de Antropologia. Política e Sociologia. São Paulo: Cortez, 1985. 